\title{
Role of Vaginal Progesterone in Prevention of Preterm Labor in Women with Previous History of One or More Previous Preterm Births
}

\author{
Ahmed Mahmoud Abdou \\ Lecturer of Gynecology and obstetrics, Faculty of Medicine, Zagazig University, Zagazig, Egypt \\ Email: olaharb2015@gmail.com
}

How to cite this paper: Abdou, A.M. (2018) Role of Vaginal Progesterone in Prevention of Preterm Labor in Women with Previous History of One or More Previous Preterm Births. Open Journal of Obstetrics and Gynecology, 8, 329-337.

https://doi.org/10.4236/ojog.2018.84036

Received: March 9, 2018

Accepted: April 7, 2018

Published: April 10, 2018

Copyright $\odot 2018$ by author and Scientific Research Publishing Inc. This work is licensed under the Creative Commons Attribution International License (CC BY 4.0)

http://creativecommons.org/licenses/by/4.0/

\begin{abstract}
Objective: To evaluate whether prophylactic administration of $200 \mathrm{mg}$ vaginal progesterone can reduce the incidence of preterm birth in women with documented history of preterm birth $<37$ weeks of gestation or not. Setting: Obstetrics and Gynecology Department, Zagazig University Hospital, Egypt. Methods: Ninety patients with previous history of preterm birth prior to 37 week presenting with singleton pregnancy between 20 - 24 weeks were randomly allocated to receive either the progesterone $200 \mathrm{mg}$ vaginal suppository or no treatment. Results: The incidence of preterm labor before 37 weeks of gestation was significantly lower in the study group than in the control group (22.2\% vs. $53.3 \%)$ especially in earlier gestational ages. While, the mean birth weight was significantly higher in the study group than in control group ( $2872.67 \pm 565.76$ gm vs. $2487.78 \pm 742.40 \mathrm{gm})$. The neonatal morbidities and mortality associated with preterm labor were significantly lower in the study group than in the control group as shown by lower incidence of neonatal RDS (13.3\% vs. $31.1 \% ; P=0.043)$ and lower incidence of the need for NICU admission (15.6\% vs. $35.5 \%$; $P=0.03)$. Conclusion: Administration of prophylactic vaginal progesterone ( $200 \mathrm{mg}$, daily) can significantly reduce the rate of preterm birth before 37, 32 and 28 wks of gestation among women with previous spontaneous preterm birth. In addition, the rates of RDS and admission to NICU were significantly decreased among infants of women assigned to progesterone treatment. Also, there was an additional benefit of vaginal progesterone for prevention of preterm birth in women who had prior spontaneous preterm birth and cervical length $<25 \mathrm{~mm}$.
\end{abstract}

\section{Keywords}

Preterm Birth, Preterm Labor, Vaginal Progesterone 


\section{Introduction}

Preterm birth, according to WHO, is defined as birth prior to 37 completed weeks of gestation. Preterm delivery is the single most important obstetrical complication leading to perinatal morbidity and mortality [1]. Preterm births account for $70 \%$ of neonatal deaths and $25 \%-50 \%$ of cases of long-term neurological impairment in children [2]. In developed countries, the prevalence of preterm birth is about $7 \%-12 \%$ of all deliveries and one third of these occur before 34 completed weeks. The prevalence in developing countries is higher [1]. There has been an increase in the incidence of preterm birth over the last decade [3].

The mechanism responsible for preterm labor is unknown. Concurrent obstetrical abnormalities like abruption-placenta, placenta previa, multiple gestation, hypertensive disorders, IUGR are identifiable only in $40 \%$ of cases, but the remainder cases occur idiopathically [4].

The first published randomized controlled trial to study the effect of progesterone for prevention of preterm birth among women at increased risk was published in 1970 by Papiernik [5]. After that, several studies were carried out to determine the effectiveness of progesterone in preventing preterm birth, some of these reported positive results of using $17 \mathrm{OH}$-progesterone caproate or vaginal progesterone in reducing the preterm delivery [6] [7] [8]. On the contrary, other studies observed no evidence of progesterone effectiveness in prevention of preterm delivery [9] [10].

Reviewing this, we conducted this study on women with documented history of preterm birth at $<37$ weeks of gestation to evaluate whether prophylactic administration of vaginal progesterone can reduce the incidence of preterm birth in such high risk population.

\section{Methods}

This prospective randomized study was conducted in the department of Obstetrics and Gynecology, Zagazig University hospital, Egypt during the period from June 2015 to June 2017.

Ninety patients with previous history of preterm birth prior to 37 week presenting with singleton pregnancy between 20 - 24 weeks were included in the study.

This study received an approval from the Institutional Review Board (IRB). Written informed consent was taken from patients after explanation of the study.

They were randomly allocated to receive either the progesterone $200 \mathrm{mg}$ vaginal suppository (Study group) or no treatment (Control group). Thus each group included 45 patients. The treatment was continued till 36 weeks of gestation or till delivery, whichever was earlier. Gestational age was calculated from the first day of her LMP and/or by ultrasound measurements before 12 weeks.

Exclusion criteria: 
1) History of uterine malformation.

2) Prophylactic cerclage operation.

3) Multiple gestations.

4) Fetal malformation.

5) Patients with PPROM.

After detailed history and systemic examination, detailed obstetrical examination was done. Speculum examination was done at the time of recruitment to note presence of any discharge and cervicovaginal swabs taken for culture and sensitivity. Routine investigations were done for all the patients followed by ultrasonography. Trans-abdominal ultrasound (TAS) was done to look for gestational age, placental localization, amniotic fluid and congenital anomalies. Trans-vaginal ultrasound (TVS) was done at 20 - 24 weeks of gestation to measure cervical length.

Patients were followed up, every two weeks till $32^{\text {th }}$ week of pregnancy and thereafter, weekly till delivery. Patients who developed preterm labor were treated by standard tocolytic therapy and dexamethasone. Gestational age at time of delivery, birth weight, and perinatal outcome were noted and compared in both groups.

\section{Statistical Analysis}

Data collected through history, clinical examination and outcome measures coded, entered and analyzed using Microsoft Excel software. Data were then imported into Statistical Package for the Social Sciences (SPSS) version 20.0 software for analysis. According to the type of data qualitative represent as number and percentage, quantitative continues group represent by mean $\pm S D$, the following tests were used to test differences for significance; Differences between frequencies (qualitative variables) and percentages in groups were compared by Chi-square test. Differences between parametric quantitative independent groups by t test. $P$ value was set at $<0.05$ for significant results $\&<0.001$ for high significant result.

\section{Results}

Ninety patients with history of previous preterm labor were selected to enter the study. They were randomly assigned to two groups; either to receive $200 \mathrm{mg}$ vaginal progesterone or no treatment. None of the women were lost during follow up.

The mean age was similar in both groups $(23.44 \pm 2.81$ years in the study group and $23.64 \pm 2.90$ years in the control group). Also BMI was similar in both groups $\left(25.01 \pm 2.87 \mathrm{~kg} / \mathrm{m}^{2}\right.$ in the study group and $25.34 \pm 2.99 \mathrm{~kg} / \mathrm{m}^{2}$ in the control group). There was no significant difference in the prevalence of previous miscarriages between groups and the prevalence of previous preterm labor was comparable in both groups. The mean sonographic cervical length at $20-24$ weeks of gestation was similar in both groups $(26.28 \pm 3.92 \mathrm{~mm}$ in the study group vs $25.75 \pm 3.92 \mathrm{~mm}$ in the control group) (Table 1 ). 
Table 1. Clinical characters.

\begin{tabular}{|c|c|c|c|c|}
\hline & & $\begin{array}{l}\text { Study group } \\
\quad \mathrm{N}=45\end{array}$ & $\begin{array}{l}\text { Control group } \\
\qquad \mathrm{N}=45\end{array}$ & $P$ \\
\hline \multicolumn{2}{|c|}{ Age (years) } & $23.44 \pm 2.81$ & $23.64 \pm 2.90$ & 0.740 \\
\hline \multicolumn{2}{|c|}{ BMI $\left(w t / m^{2}\right)$} & $25.10 \pm 2.87$ & $25.34 \pm 2.99$ & 0.709 \\
\hline \multicolumn{2}{|c|}{ Cervical length (mm) } & $26.28 \pm 3.92$ & $25.75 \pm 3.92$ & 0.518 \\
\hline \multirow{3}{*}{$\begin{array}{c}\text { Previous preterm } \\
\text { delivery }\end{array}$} & 1.00 & $26(57.7 \%)$ & $27(60.0 \%)$ & \multirow{3}{*}{0.89} \\
\hline & 2.00 & $16(35.6 \%)$ & $16(35.6 \%)$ & \\
\hline & 3.00 & $3(6.7 \%)$ & $2(4.4 \%)$ & \\
\hline \multicolumn{2}{|c|}{ Previous miscarriage } & $5(11.1 \%)$ & $6(13.3 \%)$ & 0.74 \\
\hline \multirow{2}{*}{ Cervical length } & $<25 \mathrm{~mm}$ & 20 (44.4\%) & $21(46.7 \%)$ & \multirow{2}{*}{0.83} \\
\hline & $>25 \mathrm{~mm}$ & $25(55.6 \%)$ & $24(53.3 \%)$ & \\
\hline
\end{tabular}

The incidence of preterm labor before 37 weeks of gestation was significantly lower in the study group than in the control group $(22.2 \%$ vs $53.3 \% ; P=0.002)$. While, the mean birth weight was significantly higher in the study group than in control group ( $2872.67 \pm 565.76 \mathrm{gm}$ vs $2487.78 \pm 742.40 \mathrm{gm} ; P=0.002)$.

The neonatal morbidities and mortality associated with preterm labor were significantly lower in the study group than in the control group as shown by lower incidence of neonatal RDS $(13.3 \%$ vs $31.1 \% ; P=0.043)$ and lower incidence of the need for NICU admission (15.6\% vs 35.5\%; $P=0.03$ ) (Table 2).

Regarding patients delivered prematurely in the study group; no patient delivered below 28 weeks, 3 (30\%) patients delivered between 28 weeks and 32 weeks and 7 (70\%) patients delivered between 32 weeks and 37 weeks. While in the control group; 7 (29.2\%) patients delivered before 28 weeks, 10 (41.6\%) patients delivered between 28 weeks and 32 weeks and 7 (29.2\%) patients delivered between 32 weeks and 37 weeks. Denoting significantly lower number of patients delivered in the earlier gestational age groups in patients treated with vaginal progesterone (Table 3).

There is significant association between preterm birth and short cervical length in the control group which turned to be non significant in the treatment group; the incidence of preterm labor in the control group when the cervical length was $<25 \mathrm{~mm}$ was significantly higher than in patients with cervical length $>25 \mathrm{~mm}(76.1 \%$ vs. $33.3 \% ; P=0.004)$. While in the study group, there is no significant difference in the incidence of preterm labor when cervical length is shorter or longer than $25 \mathrm{~mm}$ (20\% vs. $24 \%$; $P=0.74$ ) (Table 4 ).

\section{Discussion}

Preterm delivery is the single most important obstetric cause associated with perinatal morbidity and mortality. It is directly responsible for about $75 \%-95 \%$ of all neonatal deaths not resulting from lethal congenital malformation [8].

United States (US) Food and Drug Administration (FDA), in 2011 approved the administration of 17-hydroxyprogesterone caproate supplementation during 
Table 2. The main outcome.

\begin{tabular}{cccc}
\hline & Study group & Control group & N $=45$ \\
\hline Preterm $<37$ weeks & $10(22.2 \%)$ & $\mathrm{N}=45$ & $P$ \\
Birth weight $(\mathrm{gm})$ & $2872.67 \pm 565.76$ & $2487.78 \pm 742.40$ & $0.002^{\star}$ \\
RDS & $6(13.3 \%)$ & $14(31.1 \%)$ & $0.007^{\star}$ \\
NICU & $7(15.63 \%)$ & $16(35.6 \%)$ & $0.043^{\star}$ \\
\hline
\end{tabular}

Table 3. gestational age at time of delivery.

\begin{tabular}{ccccc}
\hline & & Study group & Control group & $P$ \\
\hline \multirow{3}{*}{$\begin{array}{c}\text { Gestational age at } \\
\text { time of delivery }\end{array}$} & $24-27 \mathrm{w}+6$ days & $0(0.0 \%)$ & $7(29.2 \%)$ & \\
& $32-36 \mathrm{w}+6$ days & $3(30.0 \%)$ & $10(41.6 \%)$ & $0.04^{*}$ \\
\end{tabular}

Table 4. Association of cervical length and preterm labor.

\begin{tabular}{lcccc}
\hline & & \multicolumn{2}{c}{ Cervical length } & \multirow{2}{*}{$P$} \\
\cline { 3 - 4 } & & $<25 \mathrm{~mm}$ & $>25 \mathrm{~mm}$ & \\
\hline \multirow{2}{*}{ Control group } & Term & $5(23.9 \%)$ & $16(66.7 \%)$ & $0.004^{*}$ \\
& Preterm & $16(76.1 \%)$ & $8(33.3 \%)$ & \\
\multirow{2}{*}{ Study group } & Term & $16(80.0 \%)$ & $19(76.0 \%)$ & \multirow{2}{*}{0.74} \\
& Preterm & $4(20.0 \%)$ & $6(24.0 \%)$ &
\end{tabular}

pregnancy to decrease the risk of recurrent preterm birth in women with a history of previous spontaneous preterm labor [11].

The mechanism of progesterone's action in second and third trimester to prevent preterm delivery is not yet clear. It has many effects on myometrium including: smooth muscles relaxation, inhibiting oxytocin action and gap junction formation [6] [12]. It also inhibits the synthesis of stimulatory prostaglandins and the expression of contraction-associated genes in myometrium [12].

The vaginal route was chosen due to its better patient compliance and better efficacy by enhanced drug delivery to target tissues.

This study is a prospective randomized trial that evaluated the effect of vaginal progesterone $200 \mathrm{mg}$ versus no treatment on prevention of spontaneous preterm labor and avoiding the perinatal morbidities in 90 women with history of previous preterm birth.

Administration of vaginal progesterone in this study showed highly significant reduction in the incidence of preterm labor (53\% in the control group and $22 \%$ in study group) and mean birth weight in study group was significantly higher than control group ( $2873 \pm 566$ gm and $2488 \pm 742$ gm respectively).

The neonatal morbidities and mortality associated with preterm labor were significantly lower in the study group than in the control group as shown by lower incidence of neonatal RDS (13.3\% and $31.1 \%$ respectively) and lower incidence 
of the need for NICU admission (15.6\% and 35.5\% respectively).

This result was in agreement with Meis et al. who conducted a clinical, randomized, double blind study on 463 patients with a previous history of preterm birth. They found that weekly injections of $250 \mathrm{mg} 17-\mathrm{OH}-$ progestrone caproate starting at 16 - 20 wks of gestation and continued to 34 wks of gestation significantly reduced preterm labor before 37 weeks of gestation. They also demonstrated that treatment with progesterone decreased rate of birth weight of $\leq 2500$ grams, intraventricular hemorrhage, necrotizing enterocolitis and need for supplemental oxygen [6].

Also, da Fonsceca et al., found that administration of $100 \mathrm{mg}$ vaginal progesterone to women with history of preterm labor, cerclage, and uterine anomalies resulted in reduction in preterm delivery rate before 34 wks of gestation and uterine contractions compared to placebo group [8].

Cetingoz et al. studied the effect of vaginal progesterone $(100 \mathrm{mg})$ adminestration to women at risk of preterm labor including: women with history of preterm birth, twin gestations and women with uterine anomalies. They observed that although preterm delivery before $34 \mathrm{wks}$ of gestation decreased significantly for women with a history of preterm birth compared to placebo group, there was no significant change in this rate for women with twin pregnancies [13].

On the other hand, O'Brien et al., observed that the administration of vaginal progesterone gel $(90 \mathrm{mg})$ compared to placebo did not reduce the rate of early preterm labor ( $\leq 32 \mathrm{wks}$ ) or the incidence of neonatal morbidity and mortality in women with a spontaneous preterm birth history [10].

Dodd et al., in Cochrane's review concluded that although administration of progesterone is associated with obvious benefits in women considered to be at increased risk of preterm birth due to either a prior preterm birth or a short cervix, there is limited data available relating to longer-term infant and childhood outcomes. So they recommended further trials in this field as mentioned by the ACOG before [14].

In this study, there was significant association between preterm birth and short cervical length in the control group which turned to be non significant in the progesterone group; the incidence of preterm labor in the control group when the cervical length was $<25 \mathrm{~mm}$ was significantly higher than in patients with cervical length $>25 \mathrm{~mm}$ (76.1\% and 33.3\% respectively), while in the study group, there is no significant difference in the incidence of preterm labor when cervical length is shorter or longer than $25 \mathrm{~mm}$ (20\% and $24 \%$ respectively).

It was in agreement with Defranco et al. who observed that, with progesterone gel (90 mg), there was significant reduction in preterm birth rate at $\leq 32$ wks of gestation and neonatal complications (admission to NICU and the length of stay in NICU) in patients with a cervical length $<28 \mathrm{~mm}$ compared with placebo group [15].

Also, in a multicenter, randomized, double-blind, placebo-controlled trial in 2011, Hassan et al., demonstrated that the administration of progesterone gel (90 
$\mathrm{mg})$ to women with singleton pregnancy and a short cervix $(10-20 \mathrm{~mm})$, starting from $20-23+6$ wks until $36+6$ wks of gestation was associated with a substantial reduction in preterm birth rate before 35,33 and 28 wks of gestation, and a significant decrease in RDS rates and the neonatal birth weight $<1500$ gm [16].

On the other hand, Azargoon et al., found that preterm birth rate in progesterone group was lower than placebo group for women with history of previous preterm birth history, however, in subgroup analysis; progesterone could not reduce the rates of preterm birth before 37 weeks and 34 weeks gestation in women with a previous history of preterm birth and short cervix [17].

Also, Grobman et al., did not observe any difference in preterm delivery rate in nulliparous women with a cervical length $\leq 30 \mathrm{~mm}$ after the administration of weekly intramuscular injections of $250 \mathrm{mg}$ 17-OHP compared with placebo [18].

More recently Alfirevic et al., in their study on patients with history of previous preterm birth and a cervical length $\leq 25 \mathrm{~mm}$, observed that vaginal suppository progesterone $(200 \mathrm{mg})$, pessary and cerclage are all equally effective in reducing the preterm birth rate, perinatal losses and neonatal morbidity [19].

Our limitation in this study was low number of patients especially women with previous spontaneous preterm birth and short cervix. Thus we recommend that another study needs to be conducted with a larger sample size on these subgroups.

\section{Conclusions}

The findings of this study showed that the administration of vaginal suppository progesterone (200 mg, daily) beginning at 20 - $24 \mathrm{wks}$ of gestation and continued to 36 wks of gestation can significantly reduce the rate of preterm birth before 37,32 and 28 wks of gestation among women with previous spontaneous preterm birth specially in earlier gestational ages and increase the mean birth weight.

In addition, the rates of RDS and admission to NICU were significantly decreased among infants of women assigned to progesterone treatment. Also, there was an additional benefit of vaginal progesterone for prevention of preterm birth in women who had prior spontaneous preterm birth and cervical length $<25$ $\mathrm{mm}$.

\section{References}

[1] Singh, U., Singh, N. and Seth, S. (2007) A Prospective Analysis of Etiology and Outcome of Preterm Labor. The Journal of Obstetrics and Gynecology of India, 57, 48-52.

[2] (2012) ACOG Practice Bulletin No. 127: Management of Preterm Labor. Obstetrics \& Gynecology, 119, 1308-1317. https://doi.org/10.1097/AOG.0b013e31825af2f0

[3] Beck, S. (2010) The Worldwide Incidence of Preterm Birth: A Systematic Review of Maternal Mortality and Morbidity. Bulletin of the World Health Organization, 88, 31-38. https://doi.org/10.2471/BLT.08.062554 
[4] Fatema, N., Elawdy, M.M., Rahman, M. and Al-Khaduric, M. (2017) Role of 17-Hydroxyprogesterone Caproate as an Adjuvant Therapy in Women with Cervical Cerclage for Prevention of Preterm Delivery: A Retrospective Matched Controlled Study. Clinical Obstetrics and Gynecology, 6, 12-16.

[5] Farine, D., Mundle, W.R. and Dodd, J. (2008) The Use of Progesterone for Prevention of Preterm Birth. Journal of Obstetrics and Gynaecology Canada, 30, 67-71. https://doi.org/10.1016/S1701-2163(16)32716-5

[6] Meis, P.J., Klebanoff, M., Thom, E., Dombrowski, M.P., Sibai, B. and Moawad, A.H. (2003) Prevention of Recurrent Preterm Delivery by 17 Alpha-Hydroxyl Progestroncaproate. The New England Journal of Medicine, 348, 2379-2385. https://doi.org/10.1056/NEJMoa035140

[7] Mackenzie, R., Walker, M., Armson, A. and Hannah, M.E. (2006) Progesterone for the Prevention of Preterm Birth among Women at Increased Risk: A Systematic Review and Meta-Analysis of Randomized Controlled Trials. American Journal of Obstetrics \& Gynecology, 194, 1234-1242. https://doi.org/10.1016/j.ajog.2005.06.049

[8] da Fonsceca, E.B., Bittar, R.E., Carvalho, M.H. and Zugaib, M. (2003) Prophylactic Administration of Progesterone by Vaginal Suppository to Reduce the Incidence of Spontaneous Preterm Birth in Women at Increased Risk: A Randomized Placebo-Controlled Double-Blind Study. American Journal of Obstetrics \& Gynecology, 188, 419-424. https://doi.org/10.1067/mob.2003.41

[9] Rouse, D.J., Caitis, S.N., Peaceman, A.M., Sciscione, A., Thom, E.A. and Spong, C.Y. (2007) A Trial of 17 Alpha-Hydroxylprogestron Caproate to Prevent Prematurity in Twins. The New England Journal of Medicine, 357, 454-461. https://doi.org/10.1056/NEJMoa070641

[10] O’Brien, J.M., Adair, C.D., Lewis, D.F., Hall, D.R., Defranco, E.A. and Fusey, S. (2007) Progesterone Vaginal Gel for the Reduction of Recurrent Preterm Birth: Primary Results from a Randomized, Double Blind, Placebo-Controlled Trial. UItrasound in Obstetrics \& Gynecology, 30, 687-696. https://doi.org/10.1002/uog.5158

[11] FDA Statement on Makena [News Release]. Silver Spring, Maryland: U.S. Department of Health and Human Services, U.S. Food and Drug Administration; March 30, 2011.

http://www.fda.gov/NewsEvents/Newsroom/PressAnnouncements/ucm249025.htm

[12] Sfakianaki, A.K. and Norwitz, E.R. (2006) Mechanisms of Progesterone Action in Inhibiting Prematurity. The Journal of Maternal-Fetal \& Neonatal Medicine, 19, 763-772. https://doi.org/10.1080/14767050600949829

[13] Cetingoz, E., Cam, C., Sakalli, M., Karateke, A., Celik, C. and Sancak, A. (2011) Progesterone Effects on Preterm Birth in High Risk Pregnancies: A Randomized Placebo-Controlled Trial. Archives of Gynecology and Obstetrics, 283, 423-429. https://doi.org/10.1007/s00404-009-1351-2

[14] Dodd, J.M., Jones, L., Flenady, V., Cincotta, R. and Crowther, C.A. (2013) Prenatal Administration of Progesterone for Preventing Preterm Birth in Women Considered to Be at Risk of Preterm Birth. The Cochrane Database of Systematic Reviews, 7, CD004947.

[15] Defranco, E.A., O’Brien, J.M., Adair, C.D., Lewis, D.F., Hall, D.R. and Fusey, S. (2007) Vaginal Progesterone Is Associated with a Decrease in Risk for Early Preterm Birth and Improved Neonatal Outcome in Women with a Short Cervix: A Secondary Analysis from a Randomized, Double Blind, Placebo-Controlled Trial. Ultrasound in Obstetrics \& Gynecology, 30, 697-705. https://doi.org/10.1002/uog.5159

[16] Hassan, S.S., Remero, R., Vidyadhan, D., Fusey, S., Baxter, J.K. and Khandelwal, M. 
(2011) Vaginal Progesterone Reduces the Rate of Preterm Birth in Women with a Sonographic Short Cervix: A Multicenter, Randomized, Double-Blind, Placebo-Controlled Trial. Ultrasound in Obstetrics \& Gynecology, 38, 18-31.

https://doi.org/10.1002/uog.9017

[17] Azargoon, A., Ghorbani, R. and Aslebahar, F. (2016) Vaginal Progesterone on the Prevention of Preterm Birth and Neonatal Complications in High Risk Women: A Randomized Placebo-Controlled Double-Blind Study. International Journal of Reproductive Biomedicine, 14, 309-316. https://doi.org/10.29252/ijrm.14.5.309

[18] Grobman, W.A., Thom, E., Spong, C.Y., Lams, J.D., Soade, G.R. and Mercer, B.M. (2012) 17 Alpha-Hydroxyl Progesterone Caproate to Prevent Prematurity in Nulliparas with Cervical Length Less than $30 \mathrm{~mm}$. American Journal of Obstetrics \& Gynecology, 207, 390-398. https://doi.org/10.1016/j.ajog.2012.09.013

[19] Alfirevic, Z., Owen, J., Carreras Moratonas, E., Sharp, A.N., Szychowski, J.M. and Goya, M. (2013) Vaginal Progesterone, Cerclage or Cervical Pessary for Preventing Preterm Birth in Asymptomatic Singleton Pregnant Women with a History of Preterm Birth and a Sonographic Short Cervix. Ultrasound in Obstetrics \& Gynecology, 41, 146-151. https://doi.org/10.1002/uog.12300 